\title{
Dissonance in music impairs spatial gait parameters in patients with Parkinson's Disease
}

Citation for published version (APA):

Fritz, T. H., Liebau, G., Löhle, M., Hartjen, B., Czech, P., Schneider, L., Sehm, B., Kotz, S. A., Ziemssen, T., Storch, A., \& Villringer, A. (2021). Dissonance in music impairs spatial gait parameters in patients with Parkinson's Disease. Journal of Parkinsons Disease, 11(1), 363-372. https://doi.org/10.3233/jpd-202413

Document status and date:

Published: 01/01/2021

DOI:

10.3233/jpd-202413

Document Version:

Publisher's PDF, also known as Version of record

Document license:

Taverne

Please check the document version of this publication:

- A submitted manuscript is the version of the article upon submission and before peer-review. There can be important differences between the submitted version and the official published version of record.

People interested in the research are advised to contact the author for the final version of the publication, or visit the DOI to the publisher's website.

- The final author version and the galley proof are versions of the publication after peer review.

- The final published version features the final layout of the paper including the volume, issue and page numbers.

Link to publication

\footnotetext{
General rights rights.

- You may freely distribute the URL identifying the publication in the public portal. please follow below link for the End User Agreement:

www.umlib.nl/taverne-license

Take down policy

If you believe that this document breaches copyright please contact us at:

repository@maastrichtuniversity.nl

providing details and we will investigate your claim.
}

Copyright and moral rights for the publications made accessible in the public portal are retained by the authors and/or other copyright owners and it is a condition of accessing publications that users recognise and abide by the legal requirements associated with these

- Users may download and print one copy of any publication from the public portal for the purpose of private study or research.

- You may not further distribute the material or use it for any profit-making activity or commercial gain

If the publication is distributed under the terms of Article $25 \mathrm{fa}$ of the Dutch Copyright Act, indicated by the "Taverne" license above, 


\title{
Dissonance in Music Impairs Spatial Gait Parameters in Patients with Parkinson's Disease
}

Thomas H. Fritz ${ }^{\mathrm{a}, \mathrm{b}, \mathrm{c}, 1, *}$, Gefion Liebau ${ }^{\mathrm{a}, 1}$, Matthias Löhle ${ }^{\mathrm{d}, \mathrm{e}}$, Berit Hartjen ${ }^{\mathrm{a}, \mathrm{f}}$, Phillip Czech ${ }^{\mathrm{a}}$, Lydia Schneider $^{\mathrm{a}}$, Bernhard Sehm ${ }^{\mathrm{a}, \mathrm{g}}$, Sonja A. Kotz ${ }^{\mathrm{a}, \mathrm{h}}$, Tjalf Ziemssen ${ }^{\mathrm{i}}$, Alexander Storch ${ }^{\mathrm{d}, \mathrm{e}, \mathrm{j}, 2, *}$ and Arno Villringer ${ }^{\mathrm{a}, 2}$

${ }^{a}$ Max Planck Institute for Human Cognitive and Brain Sciences, Leipzig, Germany

${ }^{\mathrm{b}}$ Department of Nuclear Medicine, University of Leipzig, Leipzig, Germany

${ }^{\mathrm{c}}$ Institute for Psychoacoustics and Electronic Music (IPEM), Gent, Belgium

${ }^{\mathrm{d}}$ Division of Neurodegenerative Diseases, Department of Neurology, Technische Universität Dresden,

Dresden, Germany

${ }^{\mathrm{e}}$ Department of Neurology, University of Rostock, Rostock, Germany

${ }^{\mathrm{f}}$ Department of Psychology, University of Leipzig, Leipzig, Germany

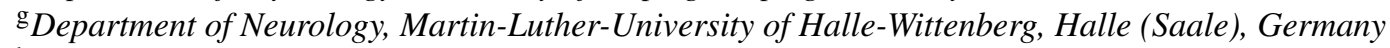

${ }^{\mathrm{h}}$ Department of Neuropsychology and Psychopharmacology, Maastricht University, Maastricht,

The Netherlands

${ }^{\mathrm{i}}$ Department of Neurology, Technische Universität Dresden, Dresden, Germany

${ }^{\mathrm{j}}$ German Centre for Neurodegenerative Diseases (DZNE) Rostock/Greifswald, Rostock, Germany

Accepted 3 November 2020

Pre-press 1 December 2020

\begin{abstract}
.
Background: It is known that music influences gait parameters in Parkinson's disease (PD). However, it remains unclear whether this effect is merely due to temporal aspects of music (rhythm and tempo) or other musical parameters.

Objective: To examine the influence of pleasant and unpleasant music on spatiotemporal gait parameters in PD, while controlling for rhythmic aspects of the musical signal.

Methods: We measured spatiotemporal gait parameters of 18 patients suffering from mild PD $(50 \%$ men, mean \pm SD age of $64 \pm 6$ years; mean disease duration of $6 \pm 5$ years; mean Unified PD Rating scale [UPDRS] motor score of $15 \pm 7$ ) who listened to eight different pieces of music. Music pieces varied in harmonic consonance/dissonance to create the experience of pleasant/unpleasant feelings. To measure gait parameters, we used an established analysis of spatiotemporal gait, which consists of a walkway containing pressure-receptive sensors (GAITRite $®$ ). Repeated measures analyses of variance were used to evaluate effects of auditory stimuli. In addition, linear regression was used to evaluate effects of valence on gait.
\end{abstract}

\footnotetext{
${ }^{1}$ These two authors contributed equally to this work and share first authorship.

${ }^{2}$ These two authors share last authorship.

${ }^{*}$ Correspondence to: Prof. Dr. Thomas H. Fritz, Max Planck Institute for Human Cognitive and Brain Sciences, Stephanstraße 1A, 04103 Leipzig, Germany. Tel.: +49 1733731465; E-mail:
}

fritz@cbs.mpg.de; Prof. Dr. Alexander Storch, Department of Neurology, University of Rostock, Gehlsheimer Strasse 20, 18147 Rostock, Germany. Tel.: +49 381494 9510; Fax: +49 381494 9512; E-mail: alexander.storch@med.uni-rostock.de. 
Results: Sensory dissonance modulated spatiotemporal and spatial gait parameters, namely velocity and stride length, while temporal gait parameters (cadence, swing duration) were not affected. In contrast, valence in music as perceived by patients was not associated with gait parameters. Motor and musical abilities did not relevantly influence the modulation of gait by auditory stimuli.

Conclusion: Our observations suggest that dissonant music negatively affects particularly spatial gait parameters in PD by yet unknown mechanisms, but putatively through increased cognitive interference reducing attention in auditory cueing.

Keywords: Parkinson's disease, gait, valence, music, dopamine

\section{INTRODUCTION}

In Parkinson's disease (PD), auditory entrainment is more effective in positively influencing gait as compared to visual or tactile stimulation [1]. One application of auditory entrainment is rhythmical auditory cueing, which seems to regulate internal timing that is deficient in PD [2-4]. Rhythmical auditory cueing has been suggested to work as an external time keeper [5]. Indeed, beneficial auditory cueing effects on gait parameters have been reported in several studies $[6,7]$. Perceiving a metronome can modulate walking parameters such as velocity [8-10], stride length [9] and cadence [9, 11]. Moreover, a metronome embedded in music also positively affects spatiotemporal gait parameters such as velocity and stride length $[5,12,13]$ but also cadence [5, 12]. Although gait improvement via rhythmic stimulation in PD seems to be linked to rhythmic skills such as synchronization performance and low synchronization variability [14], it is still unclear whether only rhythm mediates positive effects of music on gait in PD or whether other features of music also play a role. The latter seems plausible given that music has been reported to support entrainment better than metronomes at medium and fast tempi in PD patients [15].

The aesthetic appreciation of a music, so called positive valence, underlies the motivation to listen to music. In music, perceived valence is commonly modulated by a variation of consonance/dissonance $[16,17]$ : Consonant harmony (i.e., high agreement of harmonic series) is generally perceived as pleasant whereas dissonant harmony (i.e., poor agreement of harmonics) is perceived as unpleasant. This is true even for participants unfamiliar with the type of music tested, for example 'Western' music [18], suggesting that some aspects of the valence of music may be hard-wired in the human auditory pathway. Most studies investigating change in gait parameters in response to music in $\mathrm{PD}$ patients used musical stimuli that matched individual patients' preferences [5, 19, 20]. It remains unclear if the perceived valence of musical stimuli has an influence on gait. Perceived pleasantness in music has been reported to correlate with endogenous dopamine release in the striatum [21]. Given that PD patients suffer from motor deficits that correspond to dopaminergic striatal depletion [22], it is plausible that perceived pleasantness in music, which seems to be positively correlated with dopamine release, has beneficial effects on motor performance and thus on gait kinematics in PD. However, a questionnaire study revealed that perception of motor symptoms in PD is only rarely improved by music [23].

Here we aimed here at examining the influence of valence in music on spatiotemporal gait parameters in PD patients, while controlling for rhythmic aspects of the musical signal. We hypothesized that (1) valence will modulate gait in $\mathrm{PD}$, music perceived as pleasant will improve gait parameters when compared to unpleasant music, (2) music perceived as pleasant will improve spatiotemporal gait parameters compared to a beat condition, (3) music perceived to be unpleasant will deteriorate gait parameters compared to silence as it is assumed to function as an additional cognitive burden causing secondary task effects and (4) beat will improve gait parameters compared to the silence condition because of rhythmical auditory cueing effects. To dissect the various effects of the music/auditory stimuli on gait parameters, we herein differentiate harmony (consonant vs. dissonant music) from emotional valence (pleasantness/unpleasantness) as the individual perception of the presented music by study participants.

\section{METHODS}

\section{Study participants}

Participants of all ages were recruited at the Movement Disorder Outpatient Clinic at the Technische Universität Dresden between March and September 2013. The following eligibility criteria were used: idiopathic PD according to the United Kingdom PD Society Brain Bank Criteria [24], disease duration of at least one year and a disease stage of I-III (according 
to Hoehn \& Yahr [25]): Patients thus had the ability to walk without an assistive device. Furthermore, the absence of atypical and secondary Parkinsonian syndromes, drug or alcohol abuse, and neuroleptic medication were required. Further exclusion criteria were: Severe hearing deficits, presence of dementia (Montreal Cognitive Assessment (MoCA) score of $\leq 26$ [26] and depression (Beck depression Inventory (BDI-II) score $\geq 13$ [27]). Anti-Parkinsonian medication was required to have been constant for at least four weeks prior to the start of the study and had to be maintained at the usual dose throughout the study. The study was approved by the local institutional review boards at the University of Leipzig and the Technische Universität Dresden. All participants provided written informed consent and the study was approved by institutional review boards at participating sites.

\section{Clinical and neuropsychological assessments}

Prior to the experiment, we assessed basic demographic and clinical data including Hoehn and Yahr stage [25], Unified PD Rating Scale [UPDRS] part III motor score [28, 29], depression (BDI-II) [27, 30], and cognitive impairment (MoCA) [26]. Furthermore, executive function (Trail Making Test Part A and B [31, 32]), and musical ability (Montreal Battery for the Evaluation of Amusia [MBEA], published cutoff for amusia is $<20$ [33]) were assessed to examine their influence on the modulation of gait parameters by perceived valence in music. Levodopa equivalent daily doses for each patient were calculated from the current PD medication according to Tomlinson and co-workers [34].

\section{Music stimuli and experimental design}

Three stimulus categories were generated based on eight musical excerpts used in our experiment: (1) a beat without melody, (2) the same beat embedded in consonant music, and (3) the same beat embedded in dissonant music, yielding 24 musical pieces in total. The consonant and dissonant music was identical with regard to tempo and dynamic. Patients received wireless headphones and listened to the first $15 \mathrm{sec}-$ onds of each of the 24 musical pieces. They were then asked to rate the valence of the musical piece using a $12 \mathrm{~cm}$ long computer slider interface by indicating the subjective feeling of pleasantness/unpleasantness evoked by each stimulus. Patients pressed a button to confirm their evaluation and to start the next trial.

After this, patients were instructed to walk at a self-selected pace for 45 seconds, either in silence (baseline) or during musical stimulation, in a room specifically designed for an optimized experimental procedure (e.g., quiet condition, no visual cues). To measure the gait parameters, we used an established analysis system for spatiotemporal gait (GAITRite $\AA$ [35]), which consisted of a walkway of approximately

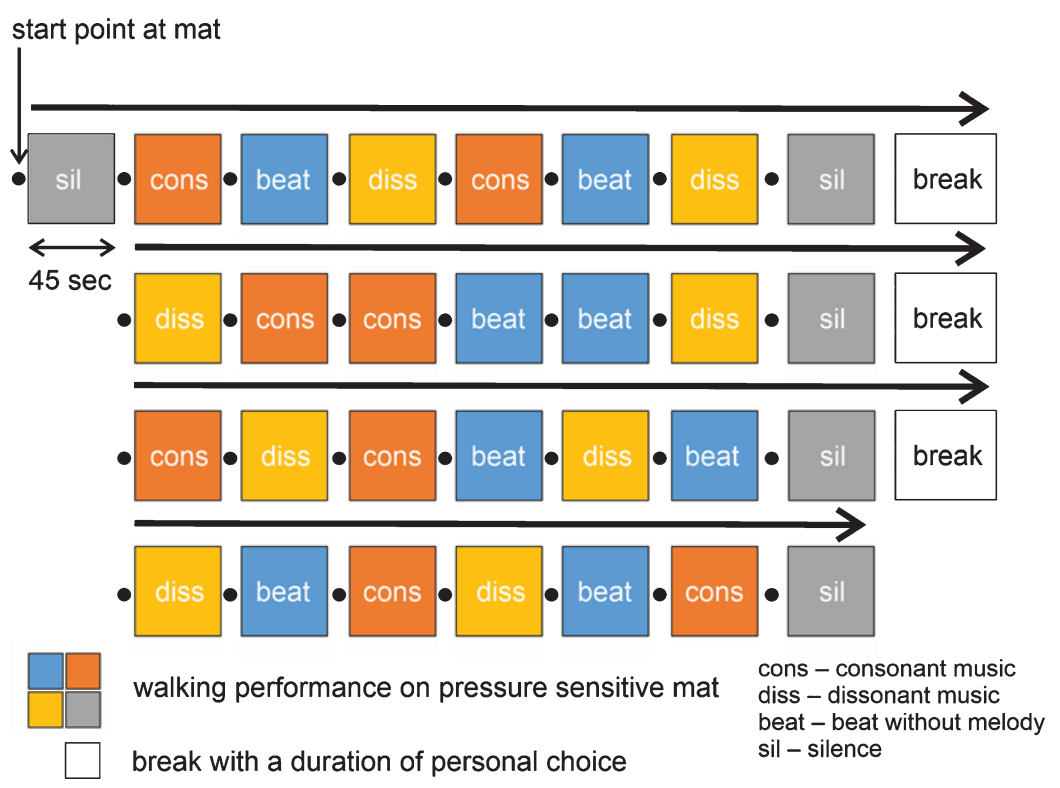

Fig. 1. Experimental design. 
10-meter length containing pressure-receptive sensors connected to a computer. Gait parameters were measured and defined as described in the GAITRite Electronic Walkway Technical Reference (WI-0215) [36] (for details, see Supplementary Methods).

Musical stimulation was presented in four blocks comprising six musical stimuli, two of each category (consonance, dissonance, beat; see Fig. 1). The order of the musical pieces was determined by a constraint randomization, under the constraints that each block included two stimuli of each category, and that each half of the experiment was in itself balanced (such that four of the eight excerpts occurred in all category variations). The latter constraint was included to allow for partial data analysis, in the case that patients were unable to continue with the experiment after the second break. Each block was preceded and followed by a silence condition (Fig. 1).

In order to control for a deterioration of performance due to drop out effects, half of the participants performed the experimental procedure with a version of the stimulus sequence, where the musical pieces were presented in reverse order. The version of stimulus sequence was randomly assigned to each participant. The experimenter was blinded with respect to experimental condition, achieved by participants listening to the presented music over headphones. As this study is the first one to study the influence of musical valence on gait in PD patients, the sample size could not be calculated on the basis of effect sizes reported in previous studies. The determination of sample size was therefore based on studies with similar research questions and experimental designs which investigated gait performance using auditory stimulation by music (on 15-21 patients) $[5,12,20]$.

\section{Statistical analysis}

The study was designed as a within-participant paradigm. A repeated-measures analysis of variance (ANOVA) was carried out on gait parameters (stride length, cadence, swing time, and velocity) as dependent measures and music categories (beat, consonant, dissonant, silence) as independent variables. The test of the model assumptions showed a normal distribution as assessed by the Kolmogorov Smirnov test and sphericity as assessed by Mauchly's test. In cases where sphericity was not given, we used the Greenhouse-Geisser correction. To investigate whether the overall effects of all music stimuli or the differential effects of the various music stimuli on gait parameters are modulated by motor or musical abilities, we computed a repeated measures analysis of covariance (ANCOVA) using the variables UPDRS and/or MBEA as continuous covariates. Post-hoc two-sided paired t-tests or repeated measures ANCOVAs were adjusted using the Bonferroni methods to avoid alpha error accumulation in multiple comparisons (in accordance with the four hypotheses tested in the experiment). Correlations of valence as rated by patients and gait parameters were assessed using Pearson's correlation test and multivariate linear regression analyses as appropriate. Values are presented as means \pm standard deviation (SD) or median and interquartile range (IQR), as appropriate. $p$ values $<0.05$ were considered statistically significant, and effect sizes Cohen's $d$ were additionally reported.

\section{RESULTS}

\section{Study participants}

In accordance with the eligibility criteria, a total of 18 PD patients (9 [50\%] men) were enrolled into this study (for details on demographics and clinical data, see Table 1). Mean \pm SD age was $64.4 \pm 6.0$ (IQR: 59-70) years with a mean disease duration of $6.1 \pm 5.0$ (IQR: $2-15$ ) years. The median Hoehn \& Yahr stage was 2 (IQR: 1.5 to 2 ) and mean UPDRS part III motor score was $15.1 \pm 6.6$ (IQR: 11-22). Most of the patients had a tremor-dominant phenotype, with the left side being slightly more affected than the right side. All patients were right-handed and wore glasses to correct vision if required; no patient required a hearing aid. Four patients had amusia as evaluated by the MBEA [33] and executive functions as measured by the Trail Making Test Part A and B were judged as not impaired [31,32] (see Table 1 for details).

\section{Valence of music stimuli}

In order to test the effects of the music categories, a repeated measures ANOVA of the rated pleasantness was carried out. We found that patients perceived a significant difference between the three musical versions $(F(2,30)=118.6, p<0.001)$. As shown in Fig. 2, the consonant versions were rated as the most pleasant, whereas dissonant versions were judged to be the least pleasant. The rhythmic beat was rated as neutral. 
Table 1

Demographic and clinical data of study cohort

\begin{tabular}{|c|c|}
\hline & Study participants \\
\hline No. of patients & 18 \\
\hline Men / Women (n, \%) & $9(50 \%) / 9(50 \%)$ \\
\hline Age $(y)$, mean $\pm S D(I Q R)$ & $64.4 \pm 6.0(59-70)$ \\
\hline Disease duration $(\mathrm{y})$, mean $\pm \mathrm{SD}(\mathrm{IQR})$ & $6.2 \pm 5.1(2-15)$ \\
\hline Hoehn \& Yahr stage, median (IQR) & $2(1.5-2)$ \\
\hline 1.5 & $8(44 \%)$ \\
\hline 2 & $6(33 \%)$ \\
\hline 2.5 & $3 / 17 \%)$ \\
\hline 3 & $1(6 \%)$ \\
\hline \multicolumn{2}{|l|}{ Parkinson's disease subtype } \\
\hline Akinetic rigid type (n, \%) & $4(22 \%)$ \\
\hline Tremor dominant type (n, \%) & $8(44 \%)$ \\
\hline Equivalent type (n, \%) & $6(33 \%)$ \\
\hline UPDRS part III motor score, mean \pm SD (IQR) & $15.1 \pm 6.6(11-22)$ \\
\hline $\mathrm{BDI}$, mean $\pm \mathrm{SD}(\mathrm{IQR})$ & $6.7 \pm 3.4(4-10)$ \\
\hline $\mathrm{MoCA}$, mean $\pm \mathrm{SD}(\mathrm{IQR})$ & $28.2 \pm 1.5(27-29)$ \\
\hline $\mathrm{MBEA}$, mean $\pm \mathrm{SD}(\mathrm{IQR})$ & $24.7 \pm 5.2(22-29)$ \\
\hline Amusia (MBEA score $<20 ; \mathrm{n}, \%$ ) & $4(22 \%)$ \\
\hline Trail Making Test (TMT) A in sec, mean $\pm \mathrm{SD}$ (IQR) & $41 \pm 14(31-47)$ \\
\hline Participants with results above normal range $(\leq 94 \mathrm{~s})^{\$}$ & $0(0 \%)^{\$}$ \\
\hline Trail Making Test (TMT) B in sec, mean \pm SD (IQR) & $83 \pm 24(66-92)$ \\
\hline Participants with results above normal range $(\leq 283 \mathrm{~s})^{\$}$ & $0(0 \%)$ \\
\hline \multicolumn{2}{|l|}{ PD treatment } \\
\hline Levodopa equivalent dose (mg per day), mean $\pm \mathrm{SD}(\mathrm{IQR})$ & $773 \pm 472(280-1156)$ \\
\hline Levodopa $(\mathrm{n}, \%)$ & $11(61 \%)$ \\
\hline COMT inhibitors (n, \%) & $2(11 \%)$ \\
\hline MAO-B inhibitors (n, \%) & $14(78 \%)$ \\
\hline Dopamine agonists (n, \%) & $16(89 \%)$ \\
\hline Amantadine (n, \%) & $4(22 \%)$ \\
\hline Deep brain stimulation $(\mathrm{n}, \%)$ & $0(0 \%)$ \\
\hline
\end{tabular}

Data are mean (SD), median (IQR), or number (\%). Levodopa equivalent doses were calculated according to Tomlinson et al. (2010) [34]. BDI, Beck's Depression Inventory; COMT, Catechol- $O$-methyltransferase; IQR, interquartile range); MAO-B, Monoaminoxidase B; MoCA, Montreal Cognitive Assessment; UPDRS, Unified PD Rating Scale. ${ }^{\$}$ Normative values of Trail Making Tests A and B generated from 287 normal adults covering the age range of our patient cohort as published by Giovagnoli and co-workers [32].

\section{Baseline gait parameters in silence}

The first trial in silence was used to assess the baseline gait parameters in our cohort of PD patients. The average gait velocity was $104.9 \pm 14.9 \mathrm{~cm} / \mathrm{s}$, stride length was $114.4 \pm 13.6 \mathrm{~cm}$, cadence was $110.8 \pm 10.2 \mathrm{steps} / \mathrm{min}$ and swing time $0.40 \pm 0.03 \mathrm{~s}$. A comparison with normal values of healthy probands [37] showed that gait performance of PD patients in our sample was significantly lower: $t_{\text {velocity }}(17)=-4.52, p<0.001 ; t_{\text {steplength }}(17)=-6.86$, $p<0.001 ; t_{\text {cadence }}(17)=-4.06, p=0.001$.

\section{Overall effects of different music stimuli on gait parameters}

We detected overall effects of the three music stimuli and silence for the parameters velocity $\left(F_{\text {velocity }}(3,37)=5.25, p=0.006\right)$, and stride length
( $\left.F_{\text {stridelength }}(3,37)=7.49, p=0.001\right)$, while the effects on cadence $\left(F_{\text {cadence }}(2,31)=3.02, p=0.067\right)$ and swing time $(F$ swingtime $(3,51)=0.73, p=0.537)$ were not significant (Fig. 3). Repeated measures ANCOVAs to assess the influence of the participants' motor abilities (as measured by UPDRS part III motor scoring) and/or musical abilities (MBEA scoring) on the overall effects of music stimuli revealed that both motor and musical abilities did not significantly affect how music stimuli modulated the spatiotemporal and spatial gait parameters velocity and stride length (Supplementary Table 1). In contrast, UPDRS part III score but not MBEA scores influenced the overall effects of music stimuli on the temporal gait parameters cadence and swing time.

Additional analyses to assess the overall association of valence and gait parameters however did not reveal any significant correlation of valence with the tested gait parameters $(r=0.105-0.237, p>0.05$; 


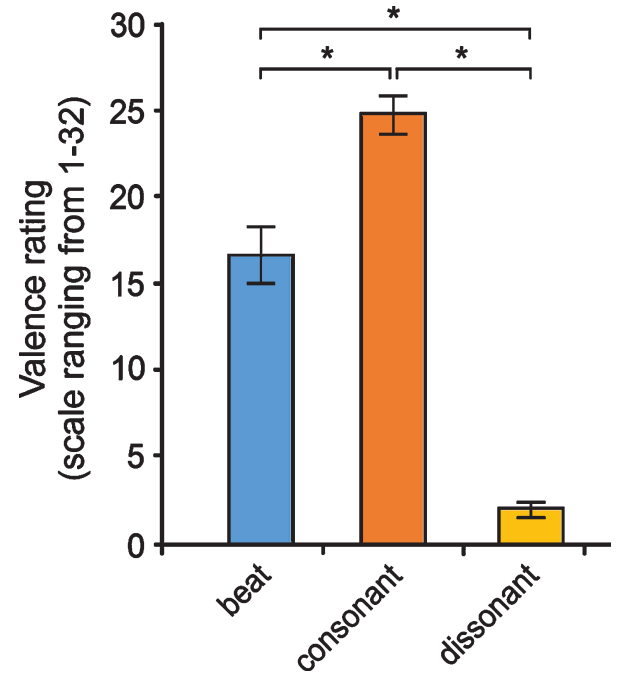

Fig. 2. Valence ratings of the three music versions by Parkinson's disease patients. Post-hoc tests using a Bonferroni correction showed that consonant music was perceived as significantly more pleasant than the beat $(p=0.001)$, while dissonant music was rated significantly more unpleasant as beat $(p<0.001)$ and consonant music $(p<0.001)$. Note: Ratings are based on a 32-point scale. Data are presented as mean values $\pm \mathrm{SD}$.

Pearson's correlation test). Multivariate linear regression analyses with type of auditory stimulus, UPDRS and/or MBEA as additional independent variable confirmed Pearson's correlation tests results (data not shown).

\section{Differential effects of various music stimuli on gait parameters}

As displayed in Fig. 3, we observed significant differences between consonant and dissonant music in spatiotemporal and spatial gait parameters with higher velocity $(p=0.021 ; d=0.3)$ and larger stride length $(p=0.026 ; d=0.2)$ with consonant as compared to dissonant music. No significant differences were detected between consonant and dissonant music in temporal gait parameters like cadence and swing time. When comparing the auditory stimulation of dissonant music with silence, we observed a significant difference in stride length with smaller stride length with dissonant music as compared to silence ( $p=0.020, d=-0.2$ ). In contrast, the comparisons of beat versus silence or consonant/dissonant music showed no significant differences in any gait parameter (Fig. 3). Repeated measures ANCOVAs with Bonferroni adjustment using the variables UPDRS and/or MBEA as continuous covariates to assess whether the differential effects of the various music stimuli on gait parameters are modulated by motor or musical abilities revealed that both motor and musical abilities did not significantly affect how the various music categories modulated gait parameters.

Further statistical analyses to assess the association of valence in music and gait parameters for the three auditory stimuli separately did not show significant correlations of valence with the tested gait parameters for all three music categories ( $p>0.05$; Pearson's correlation test). Multivariate linear regression analyses with motor ability (UPDRS part III motor score) and/or musical ability (MBEA) as additional independent variables confirmed Pearson's correlation tests results (data not shown).

\section{DISCUSSION}

The aim of this study was to investigate the influence of music on gait parameters of PD, apart from the known rhythmical effects of music. As valence (pleasantness/unpleasantness) in music has been previously reported to affect the dopamine system in healthy participants, we hypothesized that valence in music has an effect on gait parameters in PD patients, whose motor symptoms are the result of a dopamine deficiency in the basal ganglia. We thus studied the effects of various musical stimuli (silence as baseline, beat, consonant/dissonant music) on gait parameters in PD patients under highly standardized conditions. It is however important to note that an investigation of a relation of musical valence on dopamine release is not directly addressed in the current study. Moreover, dopamine release in response to music has not been studied and reported with PD patients yet.

\section{Importance of valence for effects of music on gait in $P D$}

As hypothesized in our first hypothesis, we observed that gait performance with respect to velocity (spatiotemporal gait parameter) and stride length (spatial parameter) is better when listening to consonant music than to dissonant counterparts of the same music with the same underlying beat. However, we did not detect a direct association of valence in music and gait. When we differentiate between dopamine sensitive and resistant parameters as suggested in previous studies [38, 39], our data show only effects for parameters that have previously been described as dopamine-sensitive, namely the spatiotemporal and spatial parameters velocity and stride length. Since 
A

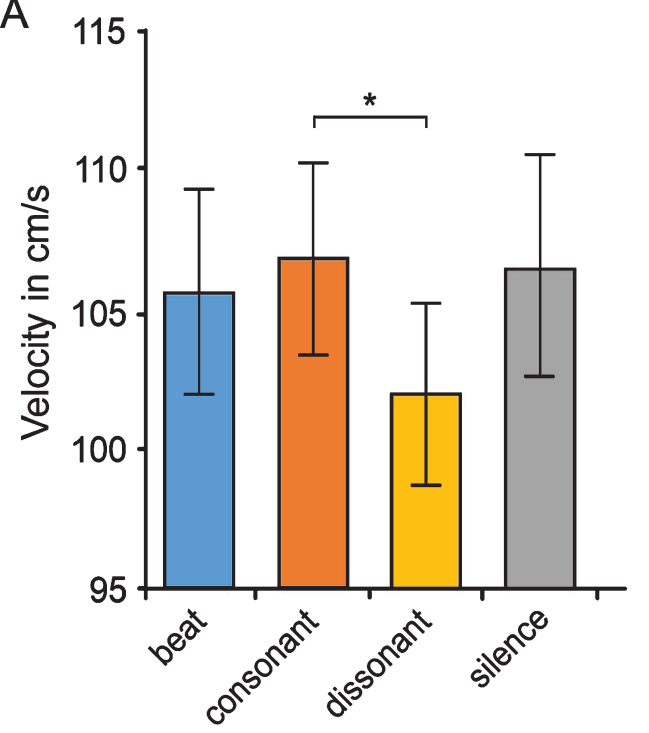

C

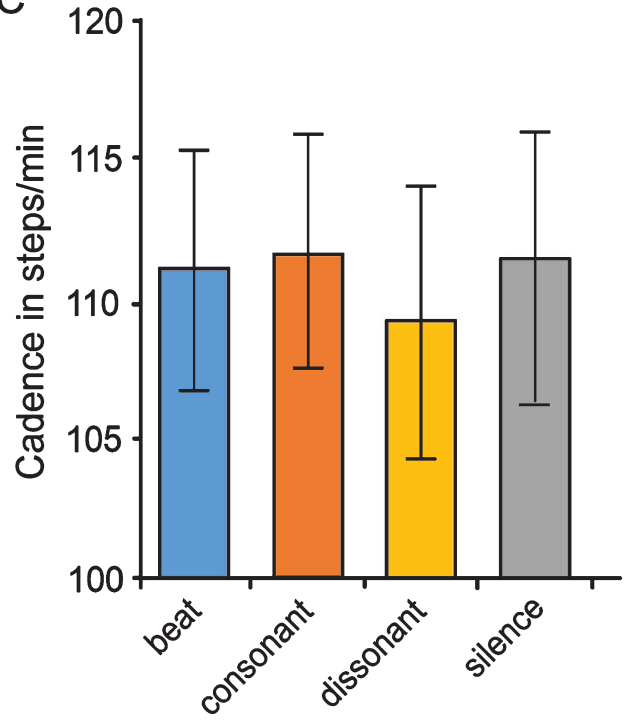

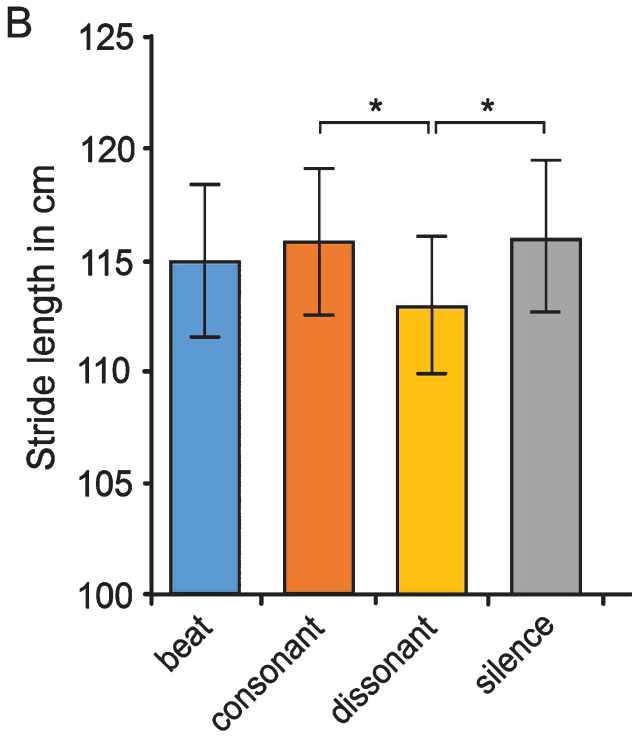

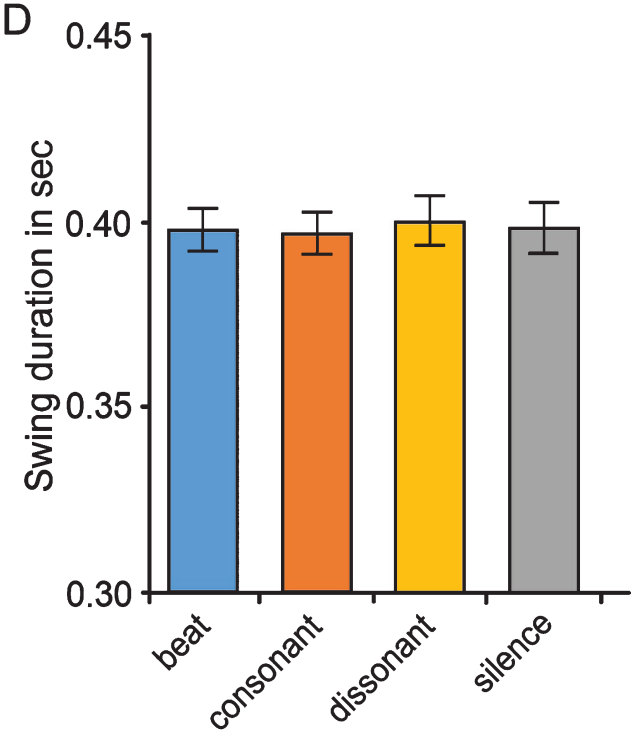

Fig. 3. Effects of various auditory stimuli on gait parameters in Parkinson's disease patients. Displayed are the effects of silence (baseline), beat, consonant and dissonant musical stimuli on spatiotemporal/spatial gait parameters (velocity [A], stride length [B]) and on temporal parameters (cadence $[\mathrm{C}]$, swing duration [D]). Post-hoc tests with Bonferroni correction revealed a significant $(*)$ difference between consonant and dissonant music for velocity $(p=0.021 ; d=0.3)$ and stride length $(p=0.026 ; d=0.2)$. Dissonant music was also shown to significantly deteriorate stride length compared to silence $(p=0.020)$. Data are presented as mean values \pm SD.

gait velocity combines both spatial and temporal aspects of gait, it is thus likely that the effects of dissonant music on gait are particularly driven by actions on spatial gait parameters. Although statistical adjustment for motor abilities of the participants (UPDRS part III scores) revealed overall effects of musical stimuli also on dopamine-resistant gait parameters (the temporal parameters cadence, swing duration), these effects did not survive pairwise comparisons of the various auditory stimuli. Conclusively, if there is a modulation of temporal gait parameters by music harmony, these actions need to be considered as minor effects. These findings are in agreement with previous research that demonstrated that dopamine is released in healthy participants during experience of peak emotion to music [21]. However, contrary to our second hypothesis, where we suspected that consonant music would improve gait parameters compared to silence, gait parameters during stimulation with consonant music showed no significant improvement 
as compared to the silence condition. Although this may signify that valence as presented here by consonant music does not change gait in PD, this might be alternatively accounted for by the fact that the PD patients participating in the current study were in a rather early disease stage (median Hoehn \& Yahr stage: 2 [IQR: 1.5-2]) and medicated leading to only mild motor symptoms (mean UPDRS motor score of only $15 \pm 7$ ). This is reflected by the high velocity values measured during the baseline (silence) condition (mean velocity was $105 \mathrm{~cm} / \mathrm{s}$ ). A comparison with values of healthy participants [37] showed that gait performance of PD patients in our sample was significantly lower, but largely exceeded those reported in previous studies on PD, which ranged from 70 to $75 \mathrm{~cm} / \mathrm{s}[5,12]$. It might thus be that in our patient cohort the PD motor deficit was relatively low, and, as a consequence, a stimulation by means of consonant music did not have any effects as compared to silence.

Negative effects of dissonant music generally perceived as unpleasant, as hypothesized in the third hypothesis, were observed in velocity and stride length and may correspond to previously described influences of musical timbre features on movement [40]. Our results with no correlations of valence as rated by the participants and gait parameters however point to the possibility that negative effects of dissonant music on spatial gait parameters is mediated by interference between listening to dissonance and motor behavior. It has been argued previously that listening to dissonant music may increase cognitive interference, resulting in a poorer performance in a Stroop interference task [41]. The current results may therefore indicate that similar interference takes place in the motor domain, an influence that may be more observable in PD patients whose motor system is more severely affected. Such large gait deterioration in PD patients as a consequence of interference has previously also been shown in a dual task condition [19]. The current results on pleasant/unpleasant auditory stimuli might therefore correspond to the role of one aspect of cognition, namely attention in auditory cueing, given that cueing strategies in PD have been reported to have large attentional effects [42].

\section{Importance of beat for effects of music on gait in $P D$}

Contrary to what we hypothesized (fourth hypothesis) and from what prior studies on auditory cueing have demonstrated $[10,11]$, our results show that the beat condition did not have any effects as compared to the silence condition on gait parameters. On the one hand, this can be explained by the fact that the PD patients participating in the current study were rather mildly affected by the disease (see above). Another interpretation of these results is that a metronome as used in the previous studies may have a more beneficial effect for PD patients than the complex rhythms applied in the current investigation. This interpretation is in line with previous assumptions that an easily discernible beat (such as a metronome) may have more beneficial effects in PD than complex rhythms [6], and is further supported by the findings that music with an embedded metronome could improve gait parameters $[5,12,13]$, whereas music without a metronome could not [19]. The absence of gait improvement in the beat condition could thus be explained by the fact that the beat consisted of a complex rhythm.

Surprisingly, while a difference in valence was observed between beat that was rated as neutral and consonance that was rated as pleasant, beat and consonant stimulation had similar effects on velocity and stride length (Fig. 3). Those data confirm the notion that valence is not directly related to gait parameters.

\section{Limitations}

Our study has several limitations that need to be addressed: Firstly, we did not run a control group consisting of matched healthy participants in parallel to the PD group to directly assess the specificity of the results for PD. Secondly, we investigated a relatively small cohort of rather mildly affected Parkinson's disease patients with an intervention scheduled at one time point, which limits the possibility to draw definite conclusions for the general population of Parkinson's disease patients, and is not sufficient to reveal whether or not advantageous effects of valence on gait parameters can be reproduced in an individual patient. Thirdly, the potential involvement of the dopamine system or cognitive interference in the effects of auditory stimuli had not been investigated in the present study. Future studies are thus warranted to dissect the factors mediating the negative effects of dissonant music on gait in PD.

\section{CONCLUSIONS}

In conclusion, we were able to demonstrate that effects of music on gait performance in PD patients 
are not only due to auditory cueing by rhythm as an external timekeeper [5]. The gait of patients walking to music with the same underlying beat correlated to the dissonance of the music, but was not associated with the perceived valence of the auditory stimuli. Together, dissonant auditory stimuli negatively affect particularly spatial gait parameters in PD putatively through increased cognitive interference reducing attention in auditory cueing. However, the mechanisms underlying the effects of musical stimuli on gait performance in PD beyond auditory cueing by easily discernible beats need to be elucidated in future studies.

\section{ACKNOWLEDGMENTS}

The authors thank all patients for their participation and the study center personnel at the Department of Neurology at the Technische Universität Dresden. This study was financially supported by the Max Planck Society and the Department of Neurology, Technische Universität Dresden. The financial sponsors of the study had no role in the study design, data collection, data analysis, data interpretation, or writing of the report. The corresponding author had the final responsibility for the decision to submit for publication.

\section{CONFLICT OF INTEREST}

GL has received a scholarship of the German Academic Scholarship Foundation and scholarship of the University of Leipzig. The authors have no conflict of interest to report related to this manuscript.

\section{SUPPLEMENTARY MATERIAL}

The supplementary material is available in the electronic version of this article: https://dx.doi.org/ 10.3233/JPD202413.

\section{REFERENCES}

[1] Lim I, Van Wegen E, De Goede C, Deutekom M, Nieuwboer A, Willems A (2005) Effects of external rhythmical cueing on gait in patients with Parkinson's disease: A systematic review. Clin Rehabil 19, 695-713.

[2] Pastor MA, Artieda J, Jahanshahi M, Obeso JA (1992) Time estimation and reproduction is abnormal in Parkinson's disease. Brain 115, 211-225.

[3] Harrington DL, Castillo GN, Greenberg PA, Song DD, Lessig S, Lee RR, Rao SM (2011) Neurobehavioral mechanisms of temporal processing deficits in Parkinson's disease. PLoS One 6, e17461.
[4] Benoit C-E, Dalla Bella S, Farrugia N, Obrig H, Mainka S, Kotz SA (2014) Musically cued gait-training improves both perceptual and motor timing in Parkinson's disease. Front Hum Neurosci 8, 1-11.

[5] Thaut MH, McIntosh GC, Rice RR, Miller RA, Rathbun J, Brault JM (1996) Rhythmic auditory stimulation in gait training for Parkinson's disease patients. Mov Disord 11, 193-200.

[6] Nombela C, Hughes LE, Owen AM, Grahn JA (2013) Into the groove: Can rhythm influence Parkinson's disease? Neurosci Biobehav Rev 37, 2564-2570.

[7] Ashoori A, Eagleman DM, Jankovic J (2015) Effects of auditory rhythm and music on gait disturbances in Parkinson's disease. Front Neurol 6, 234.

[8] del Olmo MF, Cudeiro J (2005) Temporal variability of gait in Parkinson disease: Effects of a rehabilitation programme based on rhythmic sound cues. Parkinsonism Relat Disord 11, 25-33.

[9] Willems A-M, Nieuwboer A, Chavret F, Desloovere K, Dom R, Rochester L, Jones D, Kwakkel G, van Wegen E (2006) The use of rhythmic auditory cues to influence gait in patients with Parkinson's disease, the differential effect for freezers and non-freezers, an explorative study. Disabil Rehabil 28, 721-728.

[10] Rochester L, Baker K, Hetherington V, Jones D, Willems A-M, Kwakkel G, van Wegen E, Lim I, Nieuwboer A (2010) Evidence for motor learning in Parkinson's disease: Acquisition, automaticity and retention of cued gait performance after training with external rhythmical cues. Brain Res 1319, 103-111.

[11] Freedland RL, Festa C, Sealy M, McBean A, Elghazaly P, Capan A, Brozycki L, Nelson AJ, Rothman J (2002) The effects of pulsed auditory stimulation on various gait measurements in persons with Parkinson's disease. $\mathrm{Neu}$ roRehabilitation 17, 81-87.

[12] McIntosh GC, Brown SH, Rice RR, Thaut MH (1997) Rhythmic auditory-motor facilitation of gait patterns in patients with Parkinson's disease. J Neurol Neurosurg Psychiatry 62, 22-26.

[13] Ito N, Hayashi A, Lin W, Ohkoshi N, Watanabe M, Shoji S (2000) Music therapy in Parkinson's disease: Improvement of parkinsonian gait and depression with rhythmic auditory stimulation. In Integrated Human Brain Science: Theory, Method Application (Music), Nakada T, ed. Elsevier Science, New York, pp. 435-443.

[14] Bella SD, Benoit CE, Farrugia N, Keller PE, Obrig H, Mainka S, Kotz SA (2017) Gait improvement via rhythmic stimulation in Parkinson's disease is linked to rhythmic skills. Sci Rep 7, 42005.

[15] Rose D, Delevoye-Turrell Y, Ott L, Annett LE, Lovatt PJ (2019) Music and metronomes differentially impact motor timing in people with and without Parkinson's disease: Effects of slow, medium, and fast tempi on entrainment and synchronization performances in finger tapping, toe tapping, and stepping on the spot tasks. Parkinsons Dis 2019, 6530838 .

[16] Koelsch S, Fritz T, von Cramon DY, Müller K, Friederici AD (2006) Investigating emotion with music: An fMRI study. Hum Brain Mapp 27, 239-250.

[17] Sammler D, Grigutsch M, Fritz T, Koelsch S (2007) Music and emotion: Electrophysiological correlates of the processing of pleasant and unpleasant music. Psychophysiology 44, 293-304.

[18] Fritz T, Jentschke S, Gosselin N, Sammler D, Peretz I, Turner R, Friederici AD, Koelsch S (2009) Universal 
recognition of three basic emotions in music. Curr Biol 19, 573-576.

[19] Brown LA, de Bruin N, Doan JB, Suchowersky O, Hu B (2009) Novel challenges to gait in Parkinson's disease: The effect of concurrent music in single-and dual-task contexts. Arch Phys Med Rehabil 90, 1578-1583.

[20] de Bruin N, Doan JB, Turnbull G, Suchowersky O, Bonfield $\mathrm{S}, \mathrm{Hu}$ B, Brown LA (2010) Walking with music is a safe and viable tool for gait training in Parkinson's disease: The effect of a 13-week feasibility study on single and dual task walking. Parkinsons Dis 2010, 1-9.

[21] Salimpoor VN, Benovoy M, Larcher K, Dagher A, Zatorre RJ (2011) Anatomically distinct dopamine release during anticipation and experience of peak emotion to music. Nat Neurosci 14, 257-262.

[22] Obeso JA, Rodriguez-Oroz MC, Stamelou M, Bhatia KP, Burn DJ (2014) The expanding universe of disorders of the basal ganglia. Lancet 384, 523-531.

[23] Nombela C, Rae CL, Grahn JA, Barker RA, Owen AM, Rowe JB (2013) How often does music and rhythm improve patients' perception of motor symptoms in Parkinson's disease? J Neurol 260, 1404-1405.

[24] Hughes AJ, Daniel SE, Kilford L, Lees AJ (1992) Accuracy of clinical diagnosis of idiopathic Parkinson's disease: A clinico-pathological study of 100 cases. J Neurol Neurosurg Psychiatry 55, 181-184.

[25] Hoehn MM, Yahr MD (1967) Parkinsonism: Onset, progression, and mortality. Neurology 17, 427-442.

[26] Hoops S, Nazem S, Siderowf AD, Duda JE, Xie SX, Stern MB, Weintraub D (2009) Validity of the MoCA and MMSE in the detection of MCI and dementia in Parkinson disease. Neurology 73, 1738-1745.

[27] Schrag A, Barone P, Brown RG, Leentjens AF, McDonald WM, Starkstein S, Weintraub D, Poewe W, Rascol O, Sampaio C, Stebbins GT, Goetz CG (2007) Depression rating scales in Parkinson's disease: Critique and recommendations. Mov Disord 22, 1077-1092.

[28] Goetz CG, Tilley BC, Shaftman SR, Stebbins GT, Fahn S, Martinez-Martin P, Poewe W, Sampaio C, Stern MB, Dodel R (2008) Movement Disorder Society-sponsored revision of the Unified Parkinson's Disease Rating Scale (MDSUPDRS): Scale presentation and clinimetric testing results. Mov Disord 23, 2129-2170.

[29] Fahn S, Elton RL (1987) Unified Parkinson's disease rating scale, In Recent developments in Parkinson's disease,
Fahn S, Marsden C, Calne D, Goldstein M, eds. MacMillan Health Care Information, New York, pp. 153-163.

[30] Beck AT, Steer RA, Brown GK (1996) Manual for the beck depression inventory. 2nd. The Psychological Corporation, San Antonio.

[31] Reitan RM (1958) Validity of the Trail Making Test as an indicator of organic brain damage. Percept Motor Skills $\mathbf{8}$, 271-276.

[32] Giovagnoli AR, Del Pesce M, Mascheroni S, Simoncelli M, Laiacona M, Capitani E (1996) Trail making test: Normative values from 287 normal adult controls. Ital J Neurol Sci 17, 305-309.

[33] Peretz I, Champod AS, Hyde K (2003) Varieties of musical disorders: The Montreal Battery of Evaluation of Amusia. Ann N Y Acad Sci 999, 58-75.

[34] Tomlinson CL, Stowe R, Patel S, Rick C, Gray R, Clarke CE (2010) Systematic review of levodopa dose equivalency reporting in Parkinson's disease. Mov Disord 25, 26492653.

[35] McDonough AL, Batavia M, Chen FC, Kwon S, Ziai J (2001) The validity and reliability of the GAITRite system's measurements: A preliminary evaluation. Arch Phys Med Rehabil 82, 419-425.

[36] (2013) GAITRite Electronic Walkway Technical Reference, CRI Systems, Sparta, United States.

[37] Öberg T, Karsznia A, Öberg K (1993) Basic gait parameters: Reference data for normal subjects, $10-79$ years of age. $J$ Rehabil Res Dev 30, 210-223.

[38] Blin O, Ferrandez AM, Pailhous J, Serratrice G (1991) Dopa-sensitive and dopa-resistant gait parameters in Parkinson's disease. J Neurol Sci 103, 51-54.

[39] Galna B, Lord S, Burn DJ, Rochester L (2015) Progression of gait dysfunction in incident Parkinson's disease: Impact of medication and phenotype. Mov Disord 30, 359-367.

[40] Leman M, Moelants D, Varewyck M, Styns F, van Noorden L, Martens J-P (2013) Activating and relaxing music entrains the speed of beat synchronized walking. PloS One 8, e67932.

[41] Masataka N, Perlovsky L (2013) Cognitive interference can be mitigated by consonant music and facilitated by dissonant music. Sci Rep 3, 2028.

[42] Peterson DS, Smulders K (2015) Cues and attention in parkinsonian gait: Potential mechanisms and future directions. Front Neurol 6, 255. 